\title{
Article
}

\section{Dependencies of Material Properties on Averaged Molecular Weight of a Recycled High Density Polyethylene}

\author{
Eiichi TAKATORI ${ }^{*}$, Toshitaka SHIMURA, Shigeru YAO ${ }^{* *}$, and Yoshio SHINDOH ${ }^{* * *}$ \\ "TOSOH Analysis and Research Center \\ 1-8, Kasumi, Yokka-ichi, Mie 510-8540, Japan \\ ** Department of Engineering, FUKUOKA University \\ 8-19-1 Nanakuma, Jonan-ku, FUKUOKA, 814-0180, JAPAN, \\ ${ }^{* * *}$ Shineikasei, 17-12 Umeda 5-Chome, Adachi-ku, Tokyo, 123-0851, Japan
}

\begin{abstract}
We studied the dependencies of material properties on several types of average molecular weight for a recycled high density polyethylene that was obtained from PET-bottle caps. We discussed the correlations of the average molecular weights with the density, melt index, high load melt index, yield stress, and elongation at break. We concluded that these material properties of the recycled HDPE are similar to those of the virgin HDPE with the identical average molecular weight.
\end{abstract}

Key Words: Molecular weight / Recycle high density polyethylene / Material properties / GPC

\section{リサイクル高密度ポリエチレンの材料特性の平均分子量依存性}

\author{
高取 永一 ${ }^{*}$, 志村 尚俊 ${ }^{*}$, 八尾 滋 ${ }^{* *}$, 進藤 善夫 ${ }^{* * *}$
}

(原稿受理：2013 年 6 月 14 日)

\section{1. はじめに}

プラスチックのリサイクルは, 社会的な課題として取り 組まれてきている.J. Hopewell, R. Dvorak, E. Kosior によると プラスチックのリサイクルは 1970 年代に始まっており, 既 にASTM や ISO にリサイクルの規格, 例えばASTM D5033, ISO15270 が制定されている.1) わが国おいてもプラスチック のリサイクルは 1980 年ごろには既に社会的な課題として提 起されていた.2-5)

リサイクルしたプラスチックを再度, 材料として使用す ること, すなわちマテリアルリサイクルの推進は 1980 年ご ろで既に最優先すべきリサイクル方法として想定されてい たと思われる. ${ }^{2}$ 今日, 特定家庭用機器再商品化法施行令 (平 成 20 年 12 月 5 日政令第 367 号) 第 3 条の規定にあるように, 家電リサイクル法ではマテリアルリサイクルのみをリサイ クルとして認めている. ${ }^{0}$ また, 世界各地でも回収プラスチッ クのマテリアルリサイクルに関する検討が行われている.?

マテリアルリサイクルされたプラスチックの使用拡大の ためには，一旦製品として成形され，使用された材料から 再びプラスチック材料を得た場合, その物性や構造にどの

\footnotetext{
* 株式会社 東ソー分析センター

于 $510-8540$ 三重県四日市市霞 $1-8$

Tel: 059-352-5367, E-mail: takatori@tosoh-arc.co.jp

** 福岡大学工学部化学システム工学科

*** 進栄化成株式会社
}

ような変化があるのかを知っておく必要がある。実用的に リサイクルプラスチックを材料として使用できるようにす る研究は良く行われているが，八尾らが指摘したようにリ サイクルプラスチックの物性のバージンプラスチックとの 詳細な比較に関する研究例は限られている。

高取らは市販の高密度ポリエチレン (HDPE) の分子量と分 子量分布の範囲をほぼ網羅した試料を用いて, 平均分子量

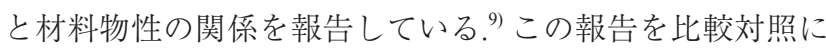
して, 本研究では最近回収運動が盛んにおこなわれている, ペットボトルのキャプ用の HDPEについて, 分子量・分 子量分布や平均分子量と物性との関係についてリサイクル HDPE とバージン HDPEの比較結果を報告する。

\section{2. 実 験}

\section{1 試料}

リサイクル HDPE の試料には進栄化成製の HDPE 製ペッ トボトルキャップのリサイクル材料から得たペレットを用 いた，対応するバージン材料としては，ペットボトルキャッ プ成形用の東ソー製のニポロンハード 4200 を用いた。用い た試料の MI と密度を Table I に示した。

\section{2 測定}

分子量測定には，東ソー製高温 GPC (HLC-8121GPC/HT) を使用した。カラム GMH-HR-H(20)HTを 3 本と, 溶離液 
1,2,4-トリクロロベンゼン（熱安定剤として，2,6-di-t-butyl - 4 - methylphenol, BHT を $0.5 \%$ 添加）を用いた。測定温度は $140{ }^{\circ} \mathrm{C}$, 試料濃度は $2 \mathrm{mg} / \mathrm{mL}$, 注入量は $300 \mu \mathrm{L}$ とした。測定 の結果得られた GPC 曲線を Fig. 1. に示した.1,000 カーボン 当りの末端メチル数短鎖分岐度は, パーキンエルマー製赤 外分光装置 1760X を用いて得たメチレン基とメチル基の比 率から計算した。酸化劣化度は, 透過型FT-IR 法により, 波 数 $1337 \mathrm{~cm}^{-1}$ でのカルボニル基による吸光度と波数 $1460 \mathrm{~cm}^{-1}$ でのメチレン基による吸光度の比として求めた. ${ }^{10,11)}$

材料特性の測定に関しては高取らの方法 ${ }^{9)}$ に準拠した. すなわち，まず圧縮成形により平板を成形し試験片を打ち 抜き, 試料片とした。圧縮成形はJIS K 6922 に準拠した。成 形温度は $190{ }^{\circ} \mathrm{C}$, 成形機からの取り出し温度は $60{ }^{\circ} \mathrm{C}$ とた. その他の条件は Table II に示した.

測定は以下の項目について行った。 すなわち，JIS K 7210 に準拠した MI（Melt Index, 荷重 $2.16 \mathrm{~kg} 190^{\circ} \mathrm{C}$ ), HLMI（High

Table I. MI and density of HDPE samples.

\begin{tabular}{|l|c|c|}
\hline & $\begin{array}{c}\mathrm{MI} \\
10 \mathrm{~g} \mathrm{~min}^{-1}\end{array}$ & $\begin{array}{c}\text { Density } \\
\mathrm{Kg} \mathrm{m}^{-3}\end{array}$ \\
\hline Recycled HDPE & 2.42 & 966 \\
\hline $\begin{array}{l}\text { Virgin HDPE } \\
\text { (Nipolon }{ }^{\circledR} \text { Hard 4200) }\end{array}$ & 2.37 & 960 \\
\hline
\end{tabular}

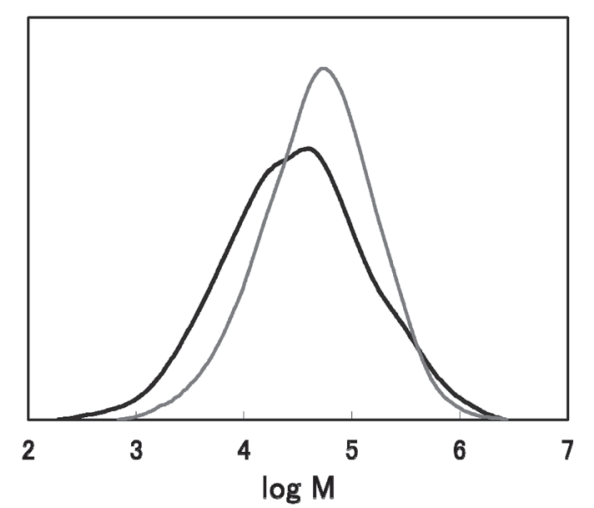

Fig. 1. GPC curves for the recycled and the virgin HDPE. The thick line represents the recycled, and the thin line the virgin.

Table II. Condition of compression molding.

\begin{tabular}{|c|c|c|}
\hline \multirow{4}{*}{ Conditon } & \multicolumn{2}{|l|}{ Plate Size } \\
\hline & \multicolumn{2}{|c|}{$160 \mathrm{~mm} \times 160 \mathrm{~mm} \times 2 \mathrm{~mm}$} \\
\hline & Gauge Pressure & Time \\
\hline & [M Pa] & [min] \\
\hline Preheating & 0 & 12 \\
\hline $\begin{array}{l}\text { First } \\
\text { Compression }\end{array}$ & 1 & 3 \\
\hline $\begin{array}{l}\text { Sencond } \\
\text { Compression }\end{array}$ & 10 & 5 \\
\hline Cooling & 10 & 10 \\
\hline
\end{tabular}

Heating temperature is 190 degree of Cellucius.

Cooling temperature is 60 degree of Cellucius.
Load Melt Index，荷重 $21.6 \mathrm{~kg} 190{ }^{\circ} \mathrm{C}$ ），JIS K 7112 に準拠した 密度勾配管による密度測定, スペクトリス（株）製 X’ pert ProMPD を用いた小角 X 線散乱測定, JIS K 6762 に準拠した 引張試験（ただし，平板より打ち抜いたダンベル試験片を 使用）を行なった，MIの測定にはペレットを使用し，その 他の特性の測定には $2 \mathrm{~mm}$ の平板を使用した.

小角 $\mathrm{X}$ 線散乱からは長周期 $D$ を求め, 結晶層と非晶層が 交互に重なり合った二層モデルを仮定して次式より結晶厚 み $L_{\mathrm{c}}$, 非晶厚み $L_{\mathrm{a}}$ を求めた。

$$
\begin{aligned}
& L \mathrm{c}=\chi_{\mathrm{C}} \times D \\
& L \mathrm{a}=\left(1-\chi_{\mathrm{C}}\right) \times D
\end{aligned}
$$

$\chi_{C}$ は結晶化度で密度 $\rho$ から次式により計算した。

$$
\chi_{\mathrm{C}}=\frac{\rho-\rho_{\mathrm{a}}}{\rho_{\mathrm{c}}-\rho_{\mathrm{a}}} \cdot \frac{\rho_{\mathrm{c}}}{\rho}
$$

ここで $\rho_{\mathrm{c}}$ は結晶密度, $\rho_{\mathrm{a}}$ は非晶密度である。各々 $\rho_{\mathrm{c}}=$ $1,000 \mathrm{~kg} \mathrm{~m}^{-3}, \rho_{\mathrm{a}}=855 \mathrm{~kg} \mathrm{~m}^{-3}$ とした.

バージン材料の平均分子量との関係について高取らの測 定結果 ${ }^{9)}$ と比較した。

\section{3. 結果と考察}

\section{1 分子量分布について}

通常の場合 GPC から得られる分子量 $M$ の分布は濃度分布, すなわち重量分布である。この際の調和平均が数平均分子量 $M_{\mathrm{n}}$, 相加平均が重量平均分子量 $M_{\mathrm{w}}$ となる。 また, 相乗平 均は $\ln M$ の算術平均 $\overline{\ln M}=\ln M_{a v}$ から計算される平均, 対 数分布平均 $M_{\mathrm{av}}$ となる. 分子量 $M$ が対数正規分布に従うと, $\ln M$ の分布から得られる標準偏差を $\sigma$ とし,

$$
\begin{aligned}
& \left(M_{w} \cdot M_{n}\right)^{0.5}=M_{\text {av }} \\
& \log \left(Q_{w}\right)=\log \left(\frac{M_{\mathrm{w}}}{M_{\mathrm{n}}}\right)=0.434 \sigma^{2}
\end{aligned}
$$

となる. ${ }^{12)} M_{\mathrm{n}}, M_{\mathrm{w}}, M_{\mathrm{av}}$ と $Q_{\mathrm{w}}=M_{\mathrm{w}} / M_{\mathrm{n}}$ の值は Table III に示した. Fig. 2. と Fig. 3. に高取らの結果 ${ }^{9)}$ と合わせて式(4)および式(5) の関係をプロットした。図中 $\triangle$ 印は高取らの結果 ${ }^{9)}$ を示し,

印がリサイクル HDPE，○印がバージン HDPE を示す。実 線は式 (4) および式 (5) が成り立つ場合の関係を示している. リサイクル HDPE もバージン HDPE も, 高取らの結果 ${ }^{9)}$ と 一致した. Fig. 1.に示したように, リサイクル HDPEの分子

\begin{tabular}{|c|c|c|c|c|}
\hline & $M_{\mathrm{n}}$ & $M_{\mathrm{w}}$ & $M_{\mathrm{av}}$ & $M_{\mathrm{w}} / M_{\mathrm{n}}$ \\
\hline Recycled HDPE & 9,800 & 90,100 & 29,100 & 9.19 \\
\hline $\begin{array}{l}\text { Virgin HDPE } \\
\text { (Nipolon } ® \text { Hard 4200) }\end{array}$ & 22,000 & 96,600 & 46,400 & 4.38 \\
\hline
\end{tabular}
量分布はバージン HDPE に比べ，広くなっているが，通常 の工業用に製造された HDPE と同様に対数正規分布として 取り扱って良いと言えよう。

Table III. Averaged molecular weight of HDPE Samples. 


\section{2 平均分子量と材料特性値との関係}

平均分子量と材料特性值との関係を示す。ここでは, 比 較する平均分子量として, $M_{\mathrm{n}}, M_{\mathrm{w}}, M_{\mathrm{av}}$ のうち, 高取らの報 告 ${ }^{9)}$ で各々の特性值と最も相関係数が高くなった平均分子量 を選んで比較した結果を示す。

\subsection{1 末端メチル数}

Fig. 4.に1,000 カーボン当りのメチル基の数で示した末端 メチル数を $\log \left(M_{\mathrm{n}}\right)$ に対してプロットした結果を示した。記 号はFig. 2. と同じである. なお, ここでの実線は, 両末端 がメチル基である場合の 1,000 カーボン当りのメチル基の数 である。リサイクル HDPEの末端メチル数は, HDPEから想 定されるよりもやや高い值を示している。低分子量成分の 量が通常の HDPEよりも多いか, 低密度ポリエチレン（LDPE あるいはLLDPE）の混入が考えられる.

なお，透過型 FT-IR 法によるカルボニル基による吸光度 とメチレン基による吸光度の比として求めた酸化劣化度は, 両者とも 0.01 で酸化劣化度に違いがなかった. 酸化劣化の 影響は無いと考えられる。

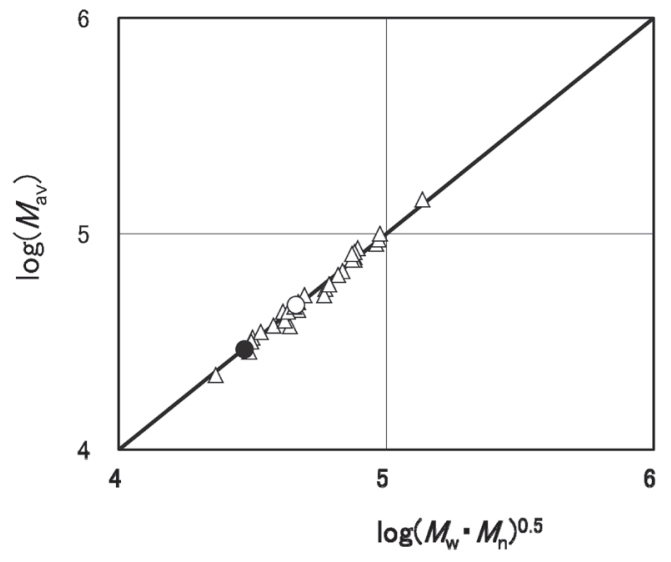

Fig. 2. Relation between $\left(M_{\mathrm{w}} \cdot M_{\mathrm{n}}\right)^{0.5}$ and $M_{\mathrm{av}} \cdot M_{\mathrm{w}}$ is the arithmetic mean (weight averaged mean) of Molecular Weight Distribution (MWD), $M_{\mathrm{n}}$ is the harmonic mean (number averaged mean) of MWD, and $M_{\mathrm{av}}$ is the logarithmic mean (geometric mean) of MWD. Open triangle symbols represent HDPEs' data of ref 9. The closed circle represents the recycled HDPE and the open circle the virgin HDPE.

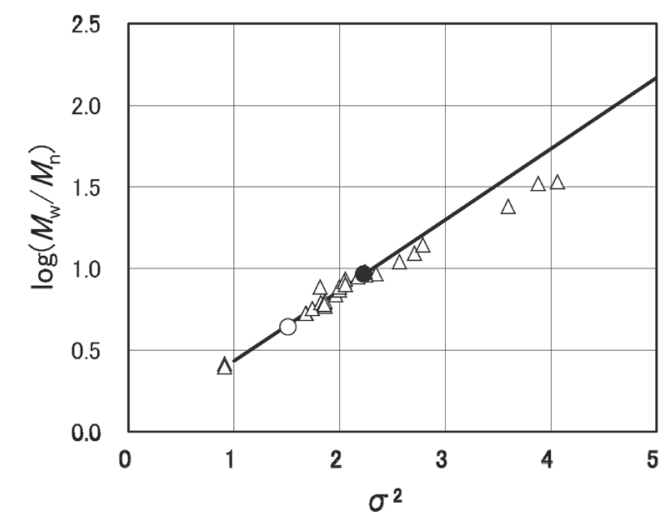

Fig. 3. Relation between $\sigma$ and $Q_{w}$. $\sigma$ is the standard deviation of logarithmic molecular weight distribution. $Q_{\mathrm{w}}$ is $M_{\mathrm{w}} / M_{\mathrm{n}}$. Symbols are same in Fig. 2.

\subsubsection{MI 及び HLMI}

Fig. 5.にはMIを, Fig. 6.には HLMI を $\log \left(M_{\mathrm{w}}\right)$ に対して プロットした結果を示した。記号は Fig. 2. と同じである。リ サイクル HDPE とバージン HDPE の両者とも高取らの結果 ${ }^{9)}$ に一致した。リサイクル HDPE とバージン HDPEの違いは, $M_{\mathrm{w}}$ の違いで説明できる程度である結果を得た。

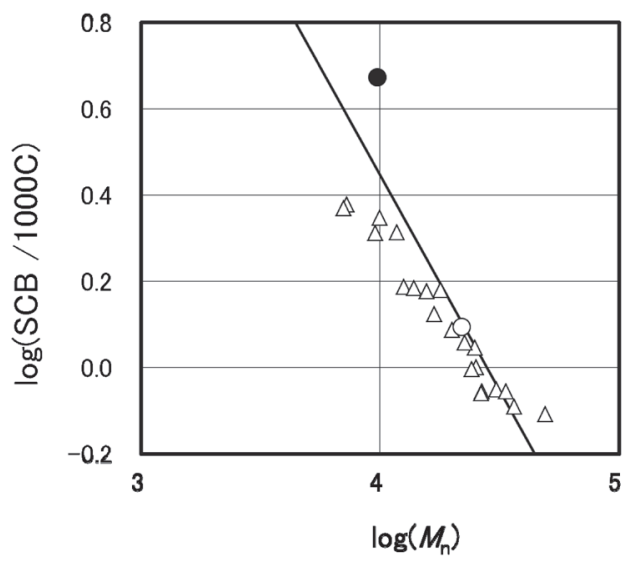

Fig. 4. Dependence of the Terminal Methyl of HDPE on the number averaged mean $M_{\mathrm{n}}$ Symbols are same in Fig. 2.

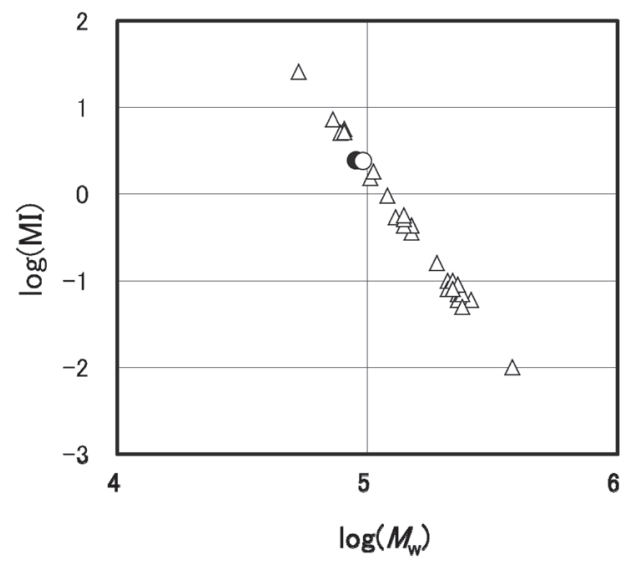

Fig. 5. Dependence of the Melt Index, MI, on the weight averaged molecular weight, $M_{\mathrm{w}}$ Symbols are same in Fig. 2.

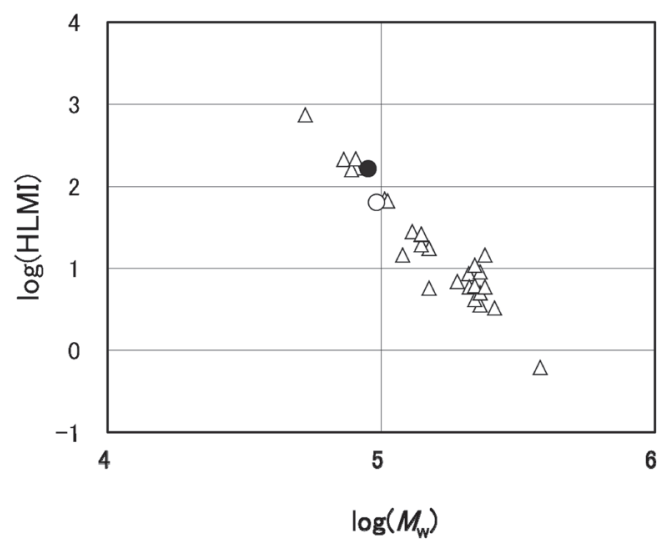

Fig. 6. Dependence of the High Load Melt Index, HLMI on the weight averaged molecular weight, $M_{\mathrm{w}}$. Symbols are same in Fig. 2. 


\subsection{3 密度及び結晶厚み $L_{\mathrm{c}}$, 非晶厚み $L_{\mathrm{a}}$}

Fig. 7. に密度 $\rho$ を $\log \left(M_{\mathrm{av}}\right)$ に対してプロットした結果を 示した。記号はFig. 2. と同じである。結晶厚み $L_{\mathrm{c}}$, 非晶厚 み $L_{\mathrm{a}}$ をプロットした結果を Fig. 8. と Fig. 9.に示した。リサ イクル HDPE とバージン HDPE の両者とも高取らの結果 ${ }^{9)}$ に一致した。リサイクル HDPE とバージン HDPEの違いは, $M_{\mathrm{av}}$ の違いで説明できる程度である結果を得た。

\subsection{4 引張試験}

Fig. 10. に引張試験の降伏応力を $\log \left(M_{\mathrm{av}}\right)$ に対してプロッ トした結果を示した。リサイクル HDPE とバージン HDPE の違いは， $M_{\mathrm{av}}$ の違いで説明できる程度である結果を得た。 このことは, 密度及び結晶厚み $L_{\mathrm{c}}$, 非晶厚み $L_{\mathrm{a}}$ の相違が $M_{\mathrm{av}}$ の違いで説明できる程度であることと整合している。

また，Fig. 11.には破断ひずみを $\log \left(M_{\mathrm{w}}\right)$ に対してプロッ トした。リサイクル HDPE とバージン HDPEの違いは, $M_{\mathrm{w}}$ の違いで説明できる程度である結果を得た。

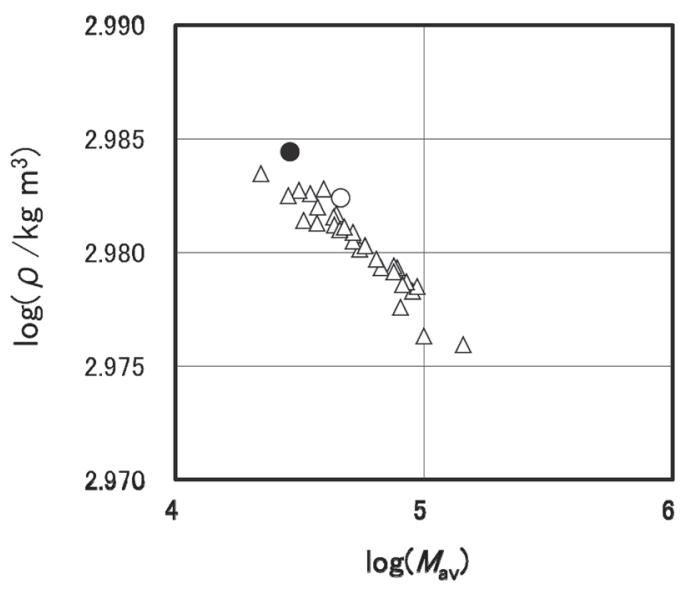

Fig. 7. Dependence of the density on the logarithmic mean, $M_{\mathrm{av}}$. Symbols are same in Fig. 2.

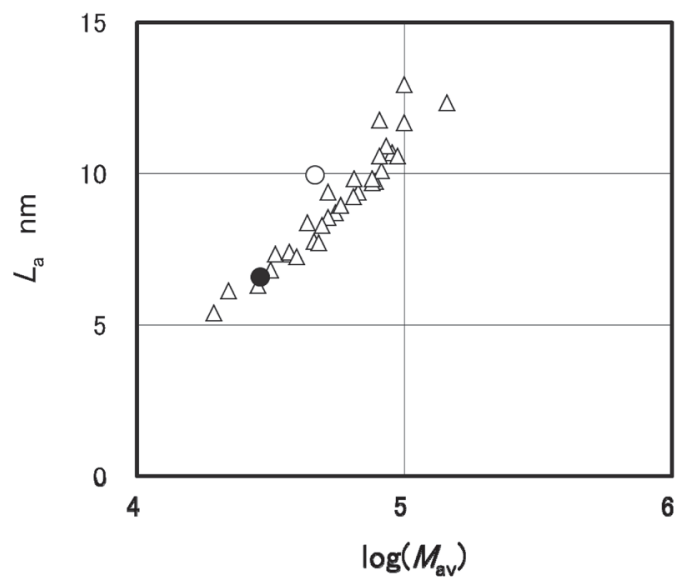

Fig. 8. Dependence of the amorphous phase length, $L_{\mathrm{a}}$, on the logarithmic mean, $M_{\mathrm{av}}$. Symbols are same in Fig. 2.

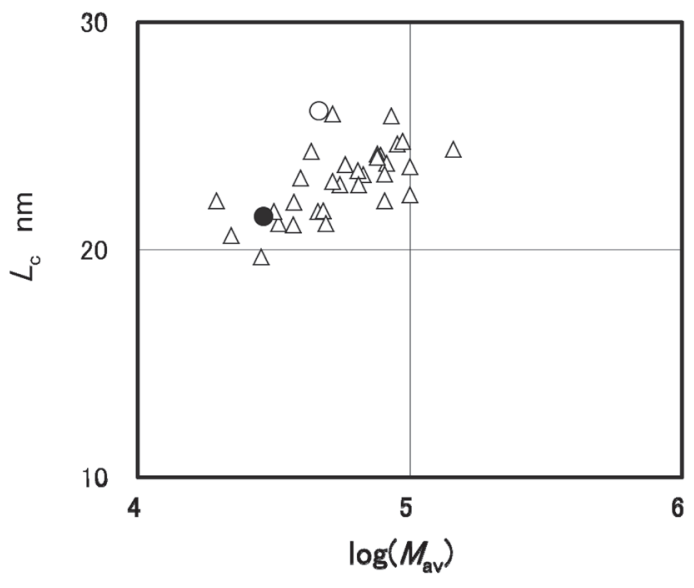

Fig. 9. Dependence of the crystal phase length, $L_{\mathrm{c}}$, on the logarithmic mean, $M_{\text {av }}$ Symbols are same in Fig. 2 .

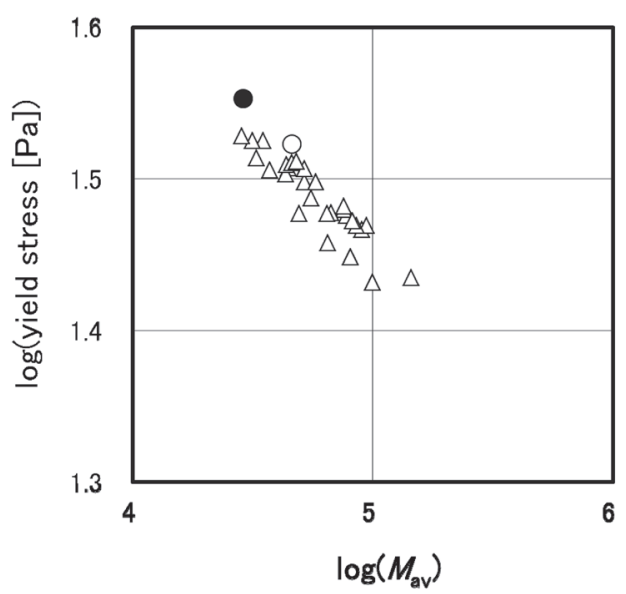

Fig. 10. Dependence of the Yield Stress on the logarithmic mean, $M_{\mathrm{av}}$ Symbols are same in Fig. 2.

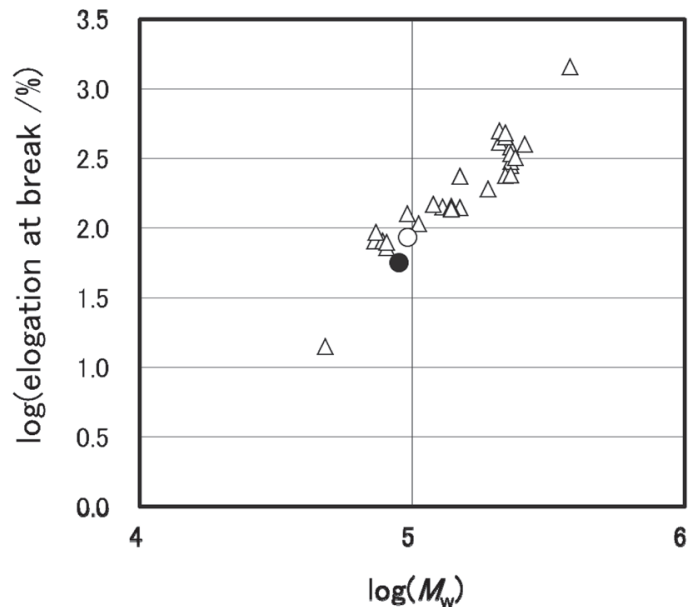

Fig. 11. Dependence of the Elongation at Break of tensile test on the weight averaged molecular weight, $M_{\mathrm{w}}$. Symbols are same in Fig. 2. 


\section{4. 結語}

リサイクル HDPE について, 分子量分布が広く, 1,000 カー ボン当りのメチル基の数が HDPEから予想されるよりやや 多いが，平均分子量に対する物性の依存性は高取らの報告 したバージン HDPE に関する結果 ${ }^{9)}$ と同じであった。リサ イクル HDPE とバージン HDPE との基礎的な物性值の差は 平均分子量の差を考慮すれば説明できる程度であると結論 できる。

\section{謝辞}

小角 X 線散乱は，（株）東ソー分析センター南陽事業部の 神岡邦和氏に測定をお願いした。データの提供に感謝する.

\section{REFERENCES}

1) Hopewell J, Dvorak R, Kosior E, PhilTransR. SocB, 364, 2115 (2009).
2) Satoh T, Nippon Gomu Kyoukaishi, 54, 329 (1981).

3) Ohiso, Y, Nippon Gomu Kyoukaishi, 54, 339 (1981).

4) Ohnuma, T, Nippon Gomu Kyoukaishi, 54, 385, (1981).

5) Saheki, K, Nippon Gomu Kyoukaishi, 54, 395 (1981).

6) "Studies on Material Recylcles and Waste Management", Report of Special Research from the National Institute for Environmental Studies, Japan (2006).

7) Ukpong EC, Peter CM, Continental J Water, Air and Soil Pollutant, 2, 31 (2011).

8) Yao S, Tominaga A, Fujikawa, Y, Sekiguchi H, Takatori E, Nihon Reoroji Gakkaisihi, 41, 173 (2013).

9) Takatoroi E, Shimura T, Yamamoto, Nihon Reoroji Gakkaishi, 36, 175 (2008).

10) Usami T, Takayama S, Polymer J, 16, 731 (1984).

11) Blitz JP, McHaddin DC, J Applied Polym Sci, 51, 13 (1994).

12) Peebles LH Jr, "Molecular Weight Distributions in Polymers", (1971) Interscience, New York, p23-p27. 